\title{
ARAŞTIRMA/RESEARCH
}

\section{KADINLARIN ANORMAL UTERIN KANAMA HAKKINDAKİ BİLGİ DURUMLARININ SAPTANMASI}

\section{Seda AKGÜN KAVURMACI *}

\section{Ayşegül GÜLBAHAR**}

\begin{abstract}
Alınıs Tarihi/Received 03.09.2019

Kabul Tarihi/Accepted 08.09.2020

Yayın Tarihi/Published 30.09.2020

Bu makaleye atıfta bulunmak için/To cite this article:

Akgün Kavurmacı S, Gülbahar A. Kadınların anormal uterin kanama hakkındaki bilgi durumlarının saptanmasi. Anadolu Hemşirelik ve Sağlı Bilimleri Dergisi, 2020;23(3): 389-396.

DOI: $10.17049 /$ ataunihem.614941

\section{$\ddot{O} Z$}

Amaç: Anormal uterin kanama, üreme çağındaki kadınların jinekoloji polikliniğine en sık başvuru nedenlerinden biridir. Kadınların hangi vasıftaki kanamayı anormal olarak değerlendirdikleri öznel bir durumdur. Bu çalışma kadınların anormal uterin kanama hakkında mevcut bilgilerini belirlemek amacıyla yapılmıştır.

Yöntem: Araş̧tırma İzmir Katip Çelebi Üniversitesi Atatürk Ĕgitim ve Araştırma Hastanesi Kadın Doğum Polikliniğinde Şubat-Mayıs 2019 tarihleri arasında tanımlayıcı olarak yapılmıştır. Araş̧ırma örneklemini 18 yaş üzeri, evli, araştırmaya katılmaya engel duyusal/psikiyatrik bir hastalı̆̆ olmayan ve araştırmaya katılmayı kabul eden 200 kadın oluşturmuştur. Araştırma verilerinin toplanmasında araştırmacı tarafindan hazırlanan anket formu kullanılmıştır. Araştırmadan elde edilen veriler SPSS 21 paket programında analiz edilmiştir. Analizde tanımlayıcı testler ve ki-kare testi kullanılmıştır.

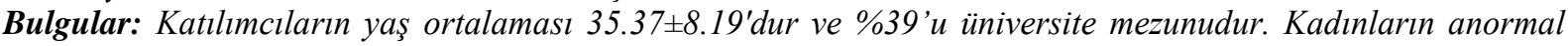
uterin kanama hakkinda özellikle süresi, sıklı̆g ve miktarı konularında bilgi düzeylerinin iyi olduğu tespit edilmişstir. Kadınların anormal uterin kanama hakkındaki bilgi düzeylerinin eğitim durumu ve yaşa göre farklllı gösterdiği saptanmıştır. Eğitim seviyesi düşük olan kadınların postkoital kanama ve intermenstrüel kanamayı daha fazla normal kabul ettiği, genç yaş grubunda olan hastaların ise kahverengi-siyah renkte kanamayı anormal bulduğu saptanmıstır.
\end{abstract}

Sonuç: Araştırma sonucunda kadınların anormal uterin kanama hakkında bilgi düzeylerinin iyi olduğu, ancak intermenstrüel ve postkoital kanama konularında bilgilendirilmeye gereksinimleri olduğu saptanmıştır. Bu amaçla sağllk çalışanları tarafindan kadınlara anormal uterin kanama bilgilendirilmelerinin yapılması etkili olabilir.

Anahtar Kelimeler: Anormal uterin kanama; bilgi düzeyi; kadın.

\section{ABSTRACT}

Determination of Women's Knowledge About Abnormal Uterine Bleeding

Aim: Abnormal uterine bleeding is one of the most common reasons for the referral of women of reproductive age to the gynaecology outpatient clinic. It is a subjective condition in which women evaluate bleeding in which characteristic. This study was conducted to determine the current knowledge of women on abnormal uterine bleeding.

Methods: This descriptive study was conducted between February and May 2019 in İzmir Katip Çelebi University Atatürk Training and Research Hospital Gynaecology Clinic. The sample of the study consisted of 200 women over the age of 18, married, without any sensory / psychiatric illness and who agreed to participate in the study. The questionnaire form prepared by the researcher was used to collect the research data. The data obtained from the study were analysed in SPSS 21 package program. Descriptive tests and chi-square test were used in the analysis.

Results: The average age of the participants is $35.37 \pm 8.19$ and $39 \%$ of them are university graduates. It was found that women have good knowledge about abnormal uterine bleeding, especially in terms of its duration, frequency and amount. It was found that the knowledge levels of women about abnormal uterine bleeding differ according to their education level and age. It was found that women with a low level of education considered postcoital bleeding and intermenstrual bleeding to be more normal, while patients in the young age group found brownblack bleeding consistent with abnormal.

Conclusion: As a result of the study, it was determined that women have good knowledge about abnormal uterine bleeding, but they need to be informed about intermenstrual and postcoital bleeding. For this purpose, we believe that it will be effective to inform abnormal uterine bleeding for women by healthcare professionals.

Keywords: Abnormal uterine bleeding; knowledge level; women;

* Sorumlu Yazar: İzmir Katip Çelebi Üniversitesi Atatürk Eğitim ve Araştırma Hastanesi Kadın Hastalıkları ve Doğum Kliniği, (Uzm. Dr.), Orcid ID: 0000-0001-9792-1786,e-posta: doctor seda @ hotmail.com

** Izmir Katip Çelebi Üniversitesi Atatürk Eğitim ve Araş̧ırma Hastanesi Kadın Hastalıkları ve Doğum 3 Servisi, (Uzm. Dr.), Orcid ID: 0000-0001-6533-6195, e-posta: draysegulgulbahar@gmail.com 


\section{GİRIS}

Anormal uterin kanama (AUK), jinekoloji polikliniğine en önemli ve en s1k başvuru nedenlerinden biridir. AUK önemli fiziksel, duygusal, cinsel, sosyal, finansal yükler yaratarak kadınların yaşam kalitesini azaltmaktadır (1). Araştırmalarda üreme dönemindeki kadınların \%14'ünün AUK'dan etkilendiği ve AUK prevalansının \%10-30 gibi geniş bir aralıkta olduğu bildirilmiştir (1-5). Farklı etiyolojiye sahip AUK semptomlarının varlığı araştırmacıları ortak bir terminoloji oluşturmaya yöneltmiştir $(6,7)$. 2011 y1lında The International Federation of Gynecology and Obstetrics (FIGO) tarafindan düzenlenen ve küresel olarak kabul gören AUK tanımı, ağır menstrüel kanama (normal popülasyonun 95. yüzdesinin üzerinde kanama), menstrüel kanama ve hem ağır hem de uzun süreli kanamaların bir kombinasyonu gibi çeşitli semptomları içermektedir $(8,9)$. Bu terminoloji ile AUK tanımı, sağlık profesyonelleri için netlik kazanmış olsada, hastaların hangi kanamaları AUK olarak kabul ettiği bilinmemektedir. Adet görme deneyimi her kadın için farklıdır ve bu nedenle, "anormal" adet kanamasının neyi ifade ettiği hastalar ve klinisyenler için öznel bir değerlendirmedir (10). Hangi kanamanın, anormal bir kanama olduğunun ve sağlik merkezine başvuru yapılması gerektiğinin öncelikle hasta tarafından saptanmas1 son derece önemlidir. Hastalara AUK'un kriterlerinin doğru aktarılması, hem sağlık merkezlerine erken başvurmalarını sağlayacak, hem de gereksiz başvuruların önüne geçecektir. $\mathrm{Bu}$ bağlamda öncelikle hastaların AUK hakkında mevcut bilgilerinin saptanması ve bu sonuçlar rehberliğinde gerekli eğitimlerin planlanması gerekmektedir. $\mathrm{Bu}$ çalışma kadınların AUK hakkında mevcut bilgilerini belirlemek amaciyla yapılmıştır. Çalışma sonuçlarının ilerde kadınlara sağlık çalışanları tarafından verilecek AUK eğitimlerinin hazırlanması için rehber olacağı düşünülmektedir.

\section{GEREÇ VE YÖNTEM \\ Araştırmanın Tipi}

Araştırma tanımlayıcı olarak gerçekleştirilmiştir.

\section{Araştırmanın Evreni ve Örneklemi}

Araştırma İzmir Katip Çelebi Üniversitesi Atatürk Eğitim ve Araştırma Hastanesi Kadın Doğum Polikliniğinde Şubat-Mayıs 2019 tarihleri arasında yapılmıştır. Araştırma evrenini belirtilen tarihlerde ilgili hastanenin kadın doğum polikliniğine başvuran 250 kadın oluşturmuştur. Araştırmanın örnekleme alınma kriterleri; 18 yaş üzerinde ve evli olmak, araştırmaya katılmaya engel duyusal/psikiyatrik bir hastalığ1 olmamak ve araştırmaya katılmayı kabul etmek olarak belirlenmiştir. Evrenin tümünün örnekleme alınması planlandığından araştırmada herhangi bir örnekleme yöntemi kullanılmamış ve araştırma örnekleme alınma kriterlerine uyan 200 kadın ile gerçekleştirilmiştir. Araştırmaya katılmayı kabul etmeme ve evli olmama gibi nedenlerle 50 hasta örneklem dışında bırakılmıştır.

\section{Veri Toplama Araçları}

Araştırma verilerinin toplanmasında araştırmacı tarafindan FIGO 2011 AUK Sistem-1 siniflamas1 ve 2018 revizyonu temel alınarak hazırlanan soru formu kullanılmıştır $(8,11)$. Ayrica soru formunda görsel olarak menstrüel piktogramdan faydalanılmıştır (12).

Soru formu: Soru formunda hastalarm tanıtıcı özellikleri, kanama süresi, sıklığı, miktarı, düzeni ve vasfi konularında sorular yer almaktadır. Veriler araştırmacı tarafından katılımcılar ile muayene öncesinde ayrı bir görüşme odasında yüz yüze görüşülerek toplanmıştır. Her bir soru formunun uygulanması yaklaşık 15-20 dakika sürmüştür.

\section{Verilerin Değerlendirilmesi}

Araştırmadan elde edilen veriler SPSS 21 paket programında analiz edilmiştir. Analizde tanımlayıcı (yüzdelik, aritmetik ortalama, standart sapma, min-max) testler ve gruplar aras1 karşılaştırmalar için t-testi ve ki-kare testi kullanılmıştır. İstatistiksel analiz sonucunda $(\mathrm{p}<0.05)$ olarak saptanan değerler anlamlı kabul edilmiştir.

\section{Araştırmanın Etik Yönü}

Araştırmaya başlamadan önce, İzmir Katip Çelebi Üniversitesi Atatürk Eğitim ve Araştırma Hastanesi Etik Kurulu'ndan (23/01/2019 tarihli karar no:017) etik kurul onayı ve araştırmanın yapılacağı merkezden yazılı izinler alınmıştır. Araştırmaya katılan kadınlara araştırma hakkında bilgi verildikten sonra araştırmaya katılmak isteyen kişilerden sözlü ve yazılı onayları alınmıştır. Araştırma verilerinin toplanması esnasında bireylere araştırma hakkında bilgi verilerek "Aydınlatılmış Onam" ilkesi, araştırmaya katılıp katılmama konusunda özgür oldukları belirtilerek "Özerkliğe Saygı" ilkesi, araştırmaya katılan bireylere bilgilerinin gizli tutulacağ1 belirtilerek "Gizlilik ve Gizliliğin Korunmas1" ilkesi yerine getirilmiştir.

\section{Araştırmanın Sınırlılıkları}

Araştırmanın yalnızca ilgili hastanenin kadın doğum polikliniğine başvuran 200 kadın ile yapılmış olması, verilerin araştırmacı tarafından 
soru -cevap yöntemi ile toplanmış olması, muayene öncesi doldurulması araştırmanın sınırlılığını oluşturmaktadır. Elde edilen veriler sadece bu örneklem için geçerlidir.

\section{BULGULAR VE TARTIŞMA}

Araştırmaya katılan kadınların yaş ortalamas1 $\quad 35.37 \pm 8.19 \quad(19-49) \quad$ olarak saptanmıştır. Katılımcıların \%27.5'i $19-29$ aralığında, \%37.5'i 30-39 aralığında ve \%35'i 4049 yaş aralığında yer almaktadır. Katılımcıların \%4.5'i okur-yazar, \%11'i ilkokul mezunu, \%23'ü lise mezunu, \%39'u üniversite mezunu, \%9.5'i yüksek lisans ve \%13'ü doktora ve üzeri eğitim seviyesine sahiptir (Tablo 1).

Katılımcıların "Sizce adet kanamasının kaç gün sürmesi anormaldir?" sorusuna; \%84'ü kanamanın 8 günden fazla sürmesini, \%37.5'i de 4 günden az sürmesini anormal olarak değerlendirmişlerdir (Tablo 1). Bu soruya verilen yanıtlar katılımcıların yaş ve eğitim durumlarına göre farkl11ık göstermemektedir (Tablo 2, Tablo 3 $\mathrm{p}>0.05$ ).

AUK, menstruasyon düzeni, süresi ve hacmindeki değişiklikleri tanımlayan geniş bir kavramdır (13). Araştırmalar, AUK prevalansının \%10-30 aralığında değiştiğini ve prevelans değerinin çalışma popülasyonuna ve AUK tanımına bağlı olduğunu göstermiştir $(2,4,14)$. AUK'da ortak bir terminoloji oluşturmak ve sinıflandırmak amacıyla menoraji, metroraji, polimenore, hipermenore, menometroraji gibi birçok terim geliştirilmiştir. Ancak bu terimlerin pratikte farklı kullanılmaları ve bu sebeple kavram kargaşasına neden olmaları klinisyenleri kolay uygulanabilir, basit bir tanımlama bulmaya itmiștir (6). FIGO tarafından 2011'de AUK tanımlama ve etiyoloji sınıflaması yapılmıştır. FIGO 2018'de AUK semptom, siniflama ve nedenlerini revize etmiştir $(8,11)$. FIGO 2018 siniflamasinda temel olarak menstrüel olmayan kanamalar ile menstrüel kanamaların sıklığı, süresi, miktarı ve düzeni tanımlanmıştır. $\mathrm{Bu}$ sınıflamaya göre, 8 gün ve daha az olması normal, fazla olması ise uzun olarak sınıflandırılmışıır (11). Araştırma sonuçları FIGO 2018 kriterleri uyumlu şekilde katılımcıların \%84'ünün 8 günden fazla kanama süresini anormal olarak belirttiğini ve kadınların bu konudaki bilgi düzeylerinin iyi olduğunu göstermektedir.

Kat1lımc1ların "Sizce iki adet kanamas1 arasındaki sürenin kaç gün olması anormaldir?" sorusuna verdikleri yanıtlar incelendiğinde ise $\% 83$ 'ünün iki siklus arasındaki sürenin 38 günden uzun sürmesini, \%44.5'inin bu sürenin 24 günden az olmasını anormal olarak değerlendirdiği tespit edilmiştir (Tablo 1). Katılımcıların yaş ve eğitim durumlarına göre bu soruya verilen yanıt istatistiksel olarak anlamlı bulunmamıştır (Tablo 2, Tablo $3 \mathrm{p}>0.05$ ).

FIGO 2018 sinıflamasında adet düzeni, bir yıl içerisinde menstrüel sikluslar arasındaki gün farkının toplamı olarak ifade edilmiştir. Menstrüel kanamanın sıklı̆g $24-38$ gün normal olarak tanımlanırken, 24 günden az olması sık, 38 günden fazla olması ise seyrek olarak tanımlanmıştır (11). Araştırma sonucu kadınların iki siklus arasındaki süre konusunda da bilgi düzeylerinin yüksek olduğunu göstermektedir.

Araştırma sonucunda katılımcıların \%84.5'inin beklenen adet tarihinden 20 gün erken ya da geç adet görülmesini anormal olarak değerlendirdiği ve bunun yaş ve eğitime göre bir farklı1ık göstermediği saptanmıştır (Tablo 1, Tablo2, Tablo 3 p >0.05).

FIGO 2018 siniflamasinda, bir yılda sikluslar arasındaki değişiklik, 2 ile 20 gün arasında ise normal, 20 günden fazla ise düzensiz olarak tanımlanmıştır. Ayrıca 90 gün içerisinde hiç kanamanın olmaması amenore olarak isimlendirilmiş ve bu kategori altında sınıflandırılmıştır. Menoraji, metroraji, oligomenore ve disfonksiyonel uterin kanama gibi tanımlamaların aksine amenore ile ilgili tartışma olmadığı ve bu tanımlamanın korunması gerektiğ konusunda görüş bildirilmiştir (11). Çalışma sonuçları FIGO 2018 sınıflaması ile uyumludur. Çalışmalarda, AUK'un hayatı tehdit edici olmadığı ve hastalar açısından AUK'un temel yükünün yaşam kalitesi üzerindeki önemli etkisi olduğu bildirilmiştir $(16,17)$. FIGO 2018 revizyonunda önceki sınıflamadaki mililitre olarak ifade edilen kanama miktarının yerine National Institute of Care Excellence (NICE) tanımlamasındaki kadının yaşam kalitesini etkileyebilecek kanama miktarı temel alınarak az, normal, fazla şeklinde hasta ifadesi tercih edilmiştir (18). Yaşam kalitesi, AUK üzerine yapılan çalışmalarda standartlaştırılmış bir şekilde ölçülmemektedir ve AUK'un yaşam kalitesi önlemleri üzerindeki etkisi hakkında ulusal bir popülasyon düzeyindeki perspektiften çok az bilgi bulunmaktadır $(16,17,19)$. 
Tablo 1. Kadınları Tanıtıcı Özellikleri ve AUK Bilgi Durumlarının Dağılımı

\begin{tabular}{|c|c|c|}
\hline Kadınları Tanıtıcı Özellikleri & n & $\%$ \\
\hline \multicolumn{3}{|l|}{ Yaş Grupları } \\
\hline $19-29$ & 55 & 27.5 \\
\hline $30-39$ & 75 & 37.5 \\
\hline $40-49$ & 70 & 35.0 \\
\hline \multicolumn{3}{|l|}{ Eğitim Durumu } \\
\hline Okur-yazar & 9 & 4.5 \\
\hline İlköğretim & 22 & 11.0 \\
\hline Lise & 46 & 23.0 \\
\hline Üniversite & 78 & 39.0 \\
\hline Yüksek lisans & 19 & 9.5 \\
\hline Doktora & 26 & 13.0 \\
\hline \multicolumn{3}{|l|}{ AUK Bilgileri } \\
\hline \multicolumn{3}{|c|}{ Sizce adet kanamasının kaç gün sürmesi anormaldir?* } \\
\hline 4 günden az & 75 & 37.5 \\
\hline 4-8 gün & 27 & 13.5 \\
\hline 8 günden fazla & 168 & 84.0 \\
\hline \multicolumn{3}{|c|}{ Sizce iki adet kanaması arasındaki sürenin kaç gün olması anormaldir?* } \\
\hline 24 günden az & 89 & 44.5 \\
\hline $24-38$ & 29 & 14.5 \\
\hline 38 günden fazla & 166 & 83.0 \\
\hline \multicolumn{3}{|c|}{$\begin{array}{l}\text { Sizce olmasını beklediğinizden kaç gün erken ya da geç adet görmek } \\
\text { anormaldir?* }\end{array}$} \\
\hline 2 gün erken ya da geç & 14 & 7.0 \\
\hline 7-8 gün erken ya da geç & 37 & 18.5 \\
\hline 10 gün erken ya da geç & 105 & 52.5 \\
\hline 20 gün erken ya da geç & 169 & 84.5 \\
\hline \multirow{2}{*}{\multicolumn{3}{|c|}{$\begin{array}{l}\text { Sizce bütün adet kanaması süresince şekilde } \\
\text { Gösterilen (UZUN PED) miktarda kanama olan hijyenik pedden toplamda kaç } \\
\text { adet kullanılması anormaldir?* }\end{array}$}} \\
\hline & & \\
\hline 2 adet & 77 & 38.5 \\
\hline 6 adet & 44 & 22.0 \\
\hline 10 adet & 56 & 28.0 \\
\hline 12 adet & 78 & 39.0 \\
\hline 14 adet & 145 & 72.5 \\
\hline \multicolumn{3}{|c|}{ Sizce aşağıda tanımlanan kanamalardan hangileri anormaldir?* } \\
\hline Postmenapozal vajinal kanama & 155 & 77.5 \\
\hline Koyu kahve-siyah renkli adet kanaması & 76 & 38.0 \\
\hline Postkoital kanama & 137 & 68.5 \\
\hline İntermenstrüel kanama & 90 & 45.0 \\
\hline
\end{tabular}

*Birden fazla seçenek işaretlenmiştir

Hastaların anormallik kavramını, "kendi rutinlerinin dışında olan" olarak kabul ettikleri de düşünüldüğünde çalışmamızın önemi bir kez daha ortaya çıkmaktadır. Ancak kanama miktarı konusunda yaş grupları arasında fark saptanmıştır. Aslında kadınların miktar kavramını kişisel tecrübelerinden yola çıkarak değerlendirdiği düşünülürse 2018 FIGO sınıflamasında yapılan değişiklik ile bu farkın giderilebileceği kanaatindeyiz. 
Tablo 2. Kadınların Yaş Gruplarına Göre AUK Bilgi Durumlarının Karşılaştııılması

\begin{tabular}{|c|c|c|c|c|c|}
\hline \multirow{3}{*}{ AUK Bilgileri } & \multicolumn{5}{|c|}{ Yaş Grupları } \\
\hline & \multirow{2}{*}{$\frac{19-29}{n}$} & \multirow{2}{*}{$\begin{array}{c}\text { 30-39 } \\
\mathbf{n}\end{array}$} & \multirow{2}{*}{$\frac{49-49}{n}$} & \multicolumn{2}{|c|}{ Test ve Anlamlılık } \\
\hline & & & & $\mathbf{t}$ & $\mathbf{p}$ \\
\hline \multicolumn{6}{|c|}{ Sizce adet kanamasının kaç gün sürmesi anormaldir? } \\
\hline 4 günden az & 10 & 5 & 12 & 4.666 & $\mathrm{p}>0.05$ \\
\hline 4-8 gün & 44 & 63 & 61 & 4.827 & $\mathrm{p}>0.05$ \\
\hline 8 günden fazla & 26 & 32 & 31 & 1.169 & $\mathrm{p}>0.05$ \\
\hline \multicolumn{6}{|c|}{ Sizce iki adet kanaması arasındaki sürenin kaç gün olması anormaldir? } \\
\hline 24 günden az & 26 & 32 & 31 & 0.275 & $\mathrm{p}>0.05$ \\
\hline 24-38 gün & 8 & 12 & 9 & 0.289 & $\mathrm{p}>0.05$ \\
\hline 38 günden fazla & 46 & 63 & 57 & 0.191 & $\mathrm{p}>0.05$ \\
\hline \multicolumn{6}{|c|}{ Sizce olmasını beklediğinizden kaç gün erken ya da geç adet görmek anormaldir? } \\
\hline 2 gün erken ya da geç & 5 & 6 & 3 & 1.127 & $\mathrm{p}>0.05$ \\
\hline 7-8 gün erken ya da geç & 10 & 15 & 12 & 0.201 & $p>0.05$ \\
\hline 10 gün erken ya da geç & 32 & 37 & 36 & 1.046 & $p>0.05$ \\
\hline 20 gün erken ya da geç & 49 & 65 & 55 & 3.032 & $p>0.05$ \\
\hline \multicolumn{6}{|c|}{$\begin{array}{l}\text { Sizce bütün adet kanaması süresince, şekilde gösterilen miktarda kanama olan hijyenik pedden } \\
\text { toplamda kaç adet kullanılması anormaldir? }\end{array}$} \\
\hline 2 adet & 25 & 28 & 24 & 1.692 & $\mathrm{p}>0.05$ \\
\hline 6 adet & 12 & 17 & 15 & 0.034 & $\mathrm{p}>0.05$ \\
\hline 10 adet & 23 & 14 & 19 & 6.208 & $\mathrm{p}<0.05$ \\
\hline 12 adet & 23 & 29 & 26 & 0.289 & $\mathrm{p}>0.05$ \\
\hline 14 adet & 37 & 55 & 53 & 1.143 & $\mathrm{p}>0.05$ \\
\hline \multicolumn{6}{|c|}{ Sizce aşağıda tanımlanan kanamalardan hangileri anormaldir? } \\
\hline Menapozdayken görülen adet kanaması & 41 & 56 & 58 & 1.773 & $\mathrm{p}>0.05$ \\
\hline Koyu kahve-siyah renkli adet kanaması & 30 & 27 & 19 & -0.179 & $\mathbf{p}<\mathbf{0 . 0 5}$ \\
\hline Postkoital kanama & 36 & 57 & 44 & 3.225 & $\mathbf{p}<0.05$ \\
\hline İntermenstrüel kanama & 24 & 32 & 34 & 0.567 & $\mathrm{p}>0.05$ \\
\hline
\end{tabular}


Tablo 3. Kadınların Eğitim Durumuna Göre AUK Bilgi Durumlarının Karşılaştırılması

\begin{tabular}{|c|c|c|c|c|c|c|c|c|}
\hline \multirow[b]{2}{*}{ AUK Bilgileri } & \multicolumn{6}{|c|}{ Eğitim Durumu } & \multicolumn{2}{|c|}{ Test ve Anlamlılık } \\
\hline & $\begin{array}{l}\text { Okur/ } \\
\text { yazar }\end{array}$ & İlkokul & $\begin{array}{l}\text { Ortaokul } \\
\text { /Lise }\end{array}$ & Üniversite & $\begin{array}{l}\text { Yüksek } \\
\text { Lisans }\end{array}$ & Doktora & Test ve & nlamlılık \\
\hline & $\mathbf{n}$ & $\mathbf{n}$ & $\mathbf{n}$ & $\mathbf{n}$ & $\mathbf{n}$ & $\mathbf{n}$ & $\mathbf{t}$ & $\mathbf{p}$ \\
\hline \multicolumn{9}{|c|}{ Sizce adet kanamasının kaç gün sürmesi anormaldir? } \\
\hline 4 günden az & 5 & 8 & 16 & 27 & 7 & 12 & 2.520 & $\mathrm{p}>0.05$ \\
\hline 4-8 gün & 4 & 4 & 6 & 8 & 2 & 3 & 8.783 & $\mathrm{p}>0.05$ \\
\hline 8 günden fazla & 6 & 20 & 37 & 67 & 16 & 22 & 3.445 & $\mathrm{p}>0.05$ \\
\hline \multicolumn{9}{|c|}{$\begin{array}{l}\text { Sizce iki adet kanaması arasındaki sürenin kaç gün olması } \\
\text { anormaldir? }\end{array}$} \\
\hline 24 günden az & 5 & 8 & 22 & 28 & 10 & 16 & 7.143 & $\mathrm{p}>0.05$ \\
\hline 24-38 gün & 1 & 4 & 7 & 11 & 2 & 4 & 0.611 & $\mathrm{p}>0.05$ \\
\hline 38 günden fazla & 7 & 18 & 34 & 68 & 15 & 24 & 5.671 & $\mathrm{p}>0.05$ \\
\hline \multicolumn{9}{|c|}{$\begin{array}{l}\text { Sizce olmasını beklediğinizden kaç gün erken ya da geç adet } \\
\text { görmek anomaldir? }\end{array}$} \\
\hline 2 gün erken ya da geç & 1 & 1 & 6 & 1 & 2 & 3 & 8.121 & $\mathrm{p}>0.05$ \\
\hline 7-8 gün erken ya da geç & 3 & 7 & 7 & 8 & 6 & 6 & 9.263 & $\mathrm{p}>0.05$ \\
\hline 10 gün erken ya da geç & 5 & 12 & 20 & 41 & 11 & 16 & 2.646 & $\mathrm{p}>0.05$ \\
\hline 20 gün erken ya da geç & 7 & 20 & 37 & 67 & 16 & 22 & 1.699 & $\mathrm{p}>0.05$ \\
\hline \multicolumn{9}{|c|}{$\begin{array}{l}\text { Sizce bütün adet kanaması süresince, şekilde gösterilen miktarda } \\
\text { kanama olan hijyenik pedden toplamda kaç adet kullanılması } \\
\text { anormaldir? }\end{array}$} \\
\hline 2 adet & 1 & 5 & 11 & 31 & 13 & 16 & 5.046 & $\mathrm{p}>0.05$ \\
\hline 6 adet & 1 & 2 & 12 & 17 & 3 & 9 & 6.049 & $\mathrm{p}>0.05$ \\
\hline 10 adet & 4 & 7 & 15 & 20 & 6 & 4 & 4.239 & $\mathrm{p}>0.05$ \\
\hline 12 adet & 4 & 9 & 20 & 24 & 10 & 11 & 4.358 & $\mathrm{p}>0.05$ \\
\hline 14 adet & 7 & 20 & 32 & 55 & 14 & 17 & 4.892 & $\mathrm{p}>0.05$ \\
\hline \multicolumn{9}{|c|}{ Sizce aşağıda tanımlanan kanamalardan hangileri anormaldir? } \\
\hline Postmenapozal vajinal kanama & 6 & 18 & 32 & 66 & 14 & 19 & 5.217 & $\mathrm{p}>0.05$ \\
\hline Koyu kahve-siyah renkli adet kanaması & 4 & 9 & 15 & 26 & 9 & 13 & 3.823 & $\mathrm{p}>0.05$ \\
\hline Postkoital kanama & 5 & 13 & 24 & 58 & 15 & 22 & 12.615 & $\mathbf{p}<\mathbf{0 . 0 5}$ \\
\hline İntermenstrüel kanama & 2 & 6 & 18 & 36 & 10 & 18 & 11.977 & $\mathrm{p}<0.05$ \\
\hline
\end{tabular}


Katılımcıların hangi kanamaları AUK ile uyumlu buldukları sorulduğunda, \%77.5'inin postmenapozal vajinal kanamay1, \%68.5'inin postkoital kanamay1, \%45'inin intermenstrüel kanamayı ve \%38'i koyu kahverengi-siyah renkte kanamayı AUK ile uyumlu bulduklarını belirtmişlerdir (Tablo 1). Genç yaş grubunda (1929 yaş), kahverengi-siyah renkte kanamayı AUK ile uyumlu bulanların sayısının diğer yaş gruplarına göre istatistiksel olarak anlamlı düzeyde yüksek olduğu saptanmıştır (Tablo 2, $\mathrm{p}=0.039$ ). Benzer şekilde postkoital kanamanın da yaşa göre gruplar arasında farklı şekilde tanımlandığı saptandı. Otuz-otuz dokuz yaş grubunda postkoital kanamay1 AUK ile uyumlu bulanların sayısının diğer yaş gruplarına göre istatistiksel olarak anlamlı düzeyde yüksek olduğu saptanmiştır (Tablo2, $\mathrm{p}=0.026$ ). Üniversite düzeyinde eğitimi olan katılımcılarda da postkoital kanama ve intermenstrüel kanamay1 AUK ile uyumlu bulanların sayısı istatistiksel olarak anlamlı düzeyde yüksek olduğu saptanmiştır (Tablo 3, p=0.026). FIGO kriterlerine göre menstrüel olmayan kanamalar; postmenapozal kanama, ara kanama, postkoital kanama, pre/post menapozal lekelenme şeklinde sınıflandırılmıştır (11). Postkoital kanama ve intermenstrüel kanama, eğitim seviyesi düşük olan kadınlarda daha fazla normal kabul edilmektedir. Konuyla ilgili olarak yapılacak

\section{KAYNAKLAR}

1. Fraser IS, Langham S, Uhl-Hochgraeber K. Health-related quality of life and economic burden of abnormal uterine bleeding. Expert Review of Obstetrics Gynecology 2009;4(2):179-89.

2. Matteson KA, Baker CA, Clark MA, Frick KD. Abnormal uterine bleeding, health status, and usual source of medical care: analyses using the Medical Expenditures Panel Survey. Journal of Womens Health 2013;22(11):959-65.

3. Frick KD, Clark MA, Steinwachs DM, Langenberg P, Stovall D, Munro MG, et al. STOPDUB Research Group. Financial and quality-oflife burden of dysfunctional uterine bleeding among women agreeing to obtain surgical treatment. Womens Health Issues 2009;19(1):708.

4. Liu Z, Doan QV, Blumenthal P, Dubois RW. A systematic review evaluating health-related quality of life, work impairment, and health care costs and utilization in abnormal uterine bleeding. Value Health 2007;10(3):173-82.

5. Shapley M, Jordan K, Croft PR. An epidemiological survey of symptoms of menstrual loss in the community. The British Journal of General Practice 2004;54(502):359-63. bilgilendirmeler ile bu hasta gruplarında erken tanı konulmasına katkı sağlayacağı düşüncesindeyiz.

\section{SONUÇ VE ÖNERILER}

Araştırma sonucunda kadınların AUK süresi, sıklığı ve miktarı konusunda bilgi durumlarının genel olarak iyi olduğu, bilgilerinin eğitim durumu ve yaşa göre farklılık gösterdiği ve özellikle ara kanama ve postkoital kanama gibi konularda bilgilendirilmeye ihtiyaçları olduğu tespit edilmiştir. Kadınların anormal uterin kanama hakkında bilgi sahibi olması, en az sağlık çalışanlarının ki kadar önemlidir. Anormal adet kanaması kavramının kişisel bir görüş olduğu unutulmamalıdır. $\mathrm{Bu}$ çalışma sonuçları doğrultusunda hasta sağlık çalışanları arasında iletişimi kolaylaştırmak için Uluslararası sinıflama ve isimlendirmeler de dikkate alınarak toplumsal bazda bir AUK siniflama/ isimlendirmenin yapılmasının ve kadınlara yönelik AUK bilgilendirilmelerinin yapılmasının etkili olacağı düşüncesindeyiz.

\section{Çıkar Çatışması}

Çalışma kapsamında herhangi bir kişisel ya da finansal çıkar çatıșması bulunmamaktadır.

\section{Yazar Katkısı}

Fikir-Tasarım: SAK ; Veri toplama: SAK, AG; Veri işleme: SAK ; Analiz ve yorum: SAK,AG; Kaynak taraması: SAK; Yazım:SAK; Eleştirel inceleme: AG.

6. Fraser IS, Critchley HOD, Munro MG, Broder MG. Can we achieve international agreement on terminologies and definitions used to describe abnormalities of menstrual bleeding? Human Reproduction 2007;22(3):635-43.

7. Fraser, IS, Critchley HO, Munro MG. Abnormal uterine bleeding: getting our terminology straight. Current Opinion in Obstetrics and Gynecology 2007;19(6):591-5.

8. Fraser IS, Critchley HO, Broder M. The FIGO recommendations on terminologies and definitions for normal and abnormal uterine bleeding. Seminars in Reproductive Medicine 2011;29(5):383-90.

9. Munro MG, Critchley HO, Fraser IS. The flexible FIGO classification concept for underlying causes of abnormal uterine bleeding. Seminars in Reproductive Medicine 2011;29(5):391-9.

10. Cheong Y, Cameron IT, Critchley HOD. Abnormal uterine bleeding. British Medical Bulletin 2017;123(1):103-14.

11. Munro MG, Critchley HOD, Fraser IS. FIGO Menstrual Disorders Committee. The two FIGO systems for normal and abnormal uterine bleeding symptoms and classification of causes of abnormal 


\section{Akgün Kavurmacı ve Gülbahar}

uterine bleeding in the reproductive years:2018 revisions. International Journal of Gynaecology and Obstetrics 2018;143(3):393-408.

12. Magnay JL, Nevatte TM, O'Brien S, Gerlinger C, Seitz C. Validation of a new menstrual pictogram (superabsorbent polymer-c version) for use with ultraslim towels is that contain superabsorbent polymers. Fertil Steril 2014;101(2):515-22.

13. Bumbuliene Z, Sragyte D, Klimasenko J, BumbulMazurek E. Abnormal uterine bleeding in adolescents: ultrasound evaluation of uterine volume. Gynecological Endocrinology 2019;35(4):356-9.

14. Lobo RA. Abnormal uterine bleeding: Ovulatory and anovulatory dysfunctional uterine bleeding, management of acute and chronic excessive bleeding.

Comprehensive gynecology 2007:5;915-31.

15. Warner PE, Critchley HO, Lumsden MA, Campbell-Brown M, Douglas A. Murray GD. Menorrhagia II: Is the $80-\mathrm{mL}$ blood loss criterion useful in management of complaint of menorrhagia? American Journal of Obstetrics and Gynecology 2004;190(5):1224-9.
16. Matteson KA. Clark MA. Questioning our questions: Do frequently asked questions adequately cover the aspects of women's lives most affected by abnormal uterine bleeding? Opinions of women with abnormal uterine bleeding participating in focus groups. Women Health 2010;50(2):195-211.

17. Clark TJ, Khan KS, Foon R, Pattison H, Bryan S, Gupta JK. Quality of life instruments in studies of menorrhagia: A systematic review. European Journal of Obstetrics Gynecology and Reproductive Biology 2002;104(2):96-104.

18. National Institute for Health and Clinical Excellence. Clinical Guideline 88; Heavy menstrual bleeding : assessment and management. Available at:

https://www.nice.org.uk/guidance/ng88 FullGuideline. pdf. Accessed March 14, 2018.

19. Rahn DD, Abed H, Sung VW, Matteson KA, Rogers RG, Morrill MY, et al. Systematic review highlights difficulty interpreting diverse clinical outcomes in abnormal uterine bleeding trials. Journal of Clinical Epidemiology 2011;64(3):293300 . 